\title{
Vulnerabilidade do aquífero à contaminação no município de Seberi/RS
}

\author{
Vulnerability assessment of contamination of the aquifer in the city of Seberi/RS
}

\section{Willian Fernando de Borba, Pedro Daniel da Cunha Kemerich, Leonidas Luis Descovi Vicato Filho, Pablo Ricardo Piceti Pretto, Carlos Eduardo Balestrin Flores, Jacson Rodrigues França, Diego Hinteholz}

Laboratório de Planejamento e Monitoramento Ambiental - LPMA/UFSM

Curso de Engenharia Ambiental da Universidade Federal de Santa Maria - UFSM/CESNORS

\section{Resumo}

A avaliação da vulnerabilidade de aquíferos à contaminação representa uma importante ferramenta para gestão dos recursos hídricos subterrâneos, pois permite identificar quais as áreas mais vulneráveis a contaminação na área em estudo. O presente artigo utilizou a metodologia GOD de avaliação da vulnerabilidade do aquífero à contaminação no município de Seberi/RS. Os resultados demonstraram que este município apresenta vulnerabilidade de baixa à alta, seguindo a direção sudoeste para nordeste. As áreas urbanas deste município detêm o maior número de informações referentes a captações e, portanto, apresenta maior confiabilidade nos resultados, apresentando vulnerabilidades baixa em sua porção sudoeste, média na porção central e alta na porção nordeste.

Palavras-chave: Gestão dos recursos hídricos subterrâneos, método GOD, vulnerabilidade do aquífero à contaminação.

\begin{abstract}
The assessment of the vulnerability of aquifers to contamination is an important tool for management of groundwater resources. This article used the GOD methodology vulnerability assessment of aquifer contamination in the Brazilian city of Seberi/RS. The results showed that this county is vulnerable from low to high, following the southwest to northeast. The urban area of this town holds the largest number of information regarding funding and therefore provides more reliable results, with lower vulnerabilities in its southwestern corner, middle and high in the central portion in the northeast portion.

Keywords: Management of groundwater resources, GOD method, vulnerability to contamination of the aquifer.
\end{abstract}




\section{INTRODUCC̃̃O}

Segundo RIBEIRO (2004), a vulnerabilidade das águas subterrâneas à poluição não é uma característica que se possa medir no terreno. $\mathrm{Na}$ raiz da sua definição está a percepção de que determinadas áreas são mais susceptíveis á contaminação do que outras, tomando em conta o grau de eficácia dos processos de atenuação natural, que variam por vezes drasticamente de um local para outro e a constituição litológica das formações onde ocorre ou poderá vir a ocorrer um fenômeno de poluição. Vulnerabilidade pode assim ser definida como o grau da potencial susceptibilidade da água subterrânea a uma fonte de poluição tópica ou difusa.

A vulnerabilidade significa a maior suscetibilidade de um aquífero de ser adversamente afetado por uma carga contaminante imposta. É um conceito inverso da capacidade de assimilação de contaminantes de um corpo receptor de água superficial, com a diferença de que os aquíferos possuem uma cobertura de substratos que proporciona uma maior proteção (FOSTER \& HIRATA, 1993).

Estudar e mapear a vulnerabilidade natural à contaminação das águas subterrâneas representa uma forma de contribuir para a espacialização e elucidação das áreas mais vulneráveis. Associando aos pontos potenciais de contaminação gerados pela sociedade, e/ou pelo tipo do ambiente natural em um determinado espaço e tempo, este tipo de ilustração dos processos sócio-naturais (mapas) que ocorrem nos recursos hídricos, serve de ferramenta no planejamento e na gestão desses.

Estudos hidrogeológicos e de vulnerabilidade natural a décadas vem sendo propostos e aplicados em todo mundo, a exemplo cita-se os Estados Unidos da América (EUA), com sua vulnerabilidade completamente mapeada através dos trabalhos realizados pela Environmental Protection Agency (EPA), em trabalho desenvolvido por ALLER et al. (1987), bem como os trabalhos desenvolvidos por RIBEIRO (2000) em Portugal.

No Brasil, conta-se com excelentes traba1hos, como IG/CETESB/DAEE (1997) que ilustra a cartografia sobre a vulnerabilidade de todo o estado de São Paulo. Estudos hidrogeológicos foram realizados na porção Sudoeste do Estado do Rio Grande do Sul, onde se inclui a Bacia Hidrográfica do Rio Santa Maria, como, por exemplo, através dos trabalhos de PRESOTTO et al. (1973), CPRM (1986) projeto borda leste, MACHADO (2005) Tese de Doutorado, e o Relatório e Mapa
Hidrogeológico do Estado MACHADO \& FREITAS, (2005), o Projeto Aquífero Guarani/PSAG (2007), além dos trabalhos realizados por NANNI et al. (2005) e NANNI (2008), que estudou e mapeou aspectos da hidrogeologia e vulnerabilidade na porção constituída pela Formação Serra Geral do Estado do Rio Grande do Sul.

A comunidade em geral apresenta uma grande preocupação quando o assunto é água subterrânea, pois várias cidades dependem das águas subterrâneas para o abastecimento público, o que tem demandado o planejamento de ações para a proteção desses recursos. Neste sentido, o mapeamento de vulnerabilidade de aquíferos tem se apresentado uma ferramenta eficiente para a gestão de recursos hídricos subterrâneos, apontando o risco de contaminação do aquífero por atividades antrópica (MEDEIROS et al., 2008).

A contaminação dos aquíferos tem se tornado um dos problemas mais preocupantes nas questões de gestão dos recursos hídricos subterrâneos, visto que são considerados reservatórios estratégicos para a humanidade. Para contornar esse problema são adotadas, em várias parte do mundo, principalmente nos países mais desenvolvidos, medidas preventivas, pois uma vez contaminado, a recuperação do aquífero é extremamente difícil e onerosa (CUTRIM \& CAMPOS, 2010).

Este artigo propõe-se avaliar e mapear a vulnerabilidade do aquífero à contaminação do município de Seberi/RS, a partir de informações de captações obtidas através da Companhia de Pesquisas de Recursos Minerais/CPRM, utilizando-se o Método GOD (G - groundwater ocorrence, O - overall litology of aquifer e D - deph of water) de FOSTER et al. (2006).

A metodologia GOD destina-se ao primeiro passo na avaliação do risco de poluição das águas subterrâneas, e destina-se, também, a priorizar, mas não substituir, ações sistemáticas de monitoramento e inspeção em campo (FOSTER \& HIRATA, 1987).

\section{MATERIAIS E MÉTODOS}

\section{I Localização da área de estudo}

O município de Seberi está situado no noroeste do estado do Rio Grande do Sul, Brasil, conforme a Figura 1, na latitude $27^{\circ} 28^{\prime} 4^{\prime \prime}$ S e longitude $53^{\circ} 24^{\prime} 09^{\prime \prime} \mathrm{O}$, com altitude de 546 metros do nível do mar, abrangendo uma área de $301 \mathrm{Km}^{2}$ e com população de 11,098 habitantes, sendo o mesmo pertencente à bacia hidrográfica 
do Rio Uruguai com clima subtropical úmido (IBGE, 2007).

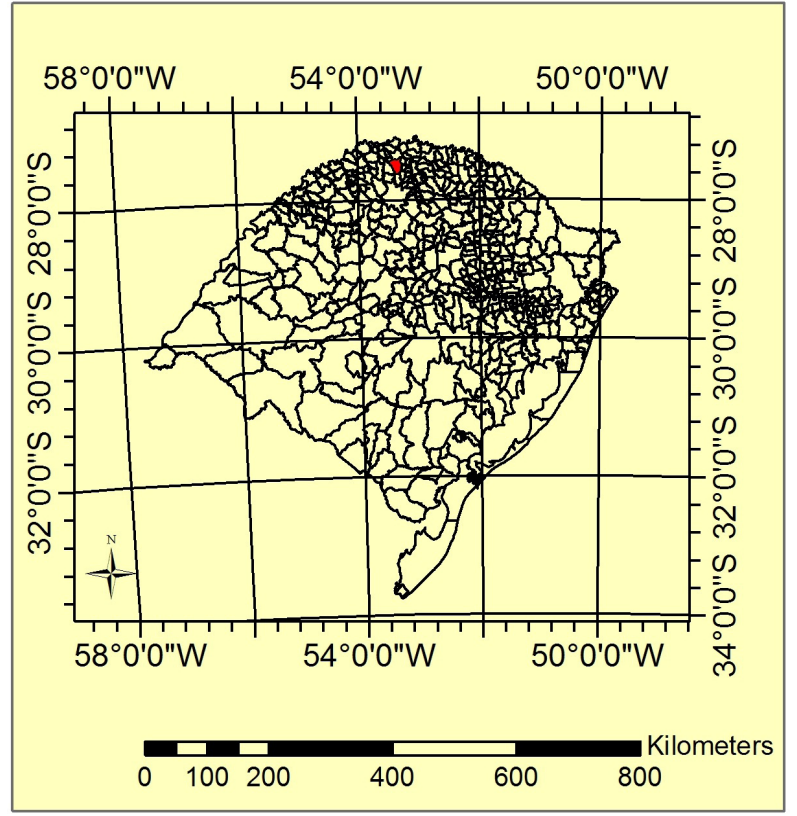

Figura 1. Localização do Município de Seberi-RS.

Para o cadastramento e obtenção de informações dos poços, foram utilizadas as informações disponibilizadas na página eletrônica http://siagasweb.cprm.gov.br/layout/ que possui um cadastro de usuários de poços subterrâneos - SIAGAS (Sistema de Informações de Águas Subterrâneas).

Desse modo, foi elaborado um banco de dados, com o uso do programa Excel 2007, conforme o quadro 1 , constando as seguintes informações: latitude e longitude (no Sistema de Coordenadas Geográficas e Sistema Universal Transversa de Mercator-UTM), código do poço, nível estático e outras informações.

O banco de dados hidrogeológico contem informações referentes a 07 captações através de poços tubulares profundos.

Para a determinação da vulnerabilidade do aquífero (recursos hídricos subterrâneos) à contaminação utilizou-se a metodologia "GOD" ( $\mathrm{G}$ - groundwater hydraulic confinement; $\mathrm{O}$ overlaying strata; D - depth to groundwater table), elaborada por FOSTER et al., (2006), correspondente a: G - Grau de confinamento hidráulico da água subterrânea/aquífero; $\mathrm{O}$ - Ocorrência de extratos de cobertura; D - Distância/Profundidade até o lençol freático, foi a metodologia utilizada para a definição dos índices de vulnerabilidade das diferentes áreas. A estimativa do índice de vulnerabilidade "GOD" seguiu as etapas ilustradas conforme a Figura 1.

Inicialmente identificou-se o grau de confinamento hidráulico do aquífero, atribuindo-lhe um índice entre 0,0 a 1,0 . Foram considerados confinados obtendo nota 0,2 , e aqueles semi-confinados nota 0,4 .

Especificaram-se as características do substrato que recobre a zona saturada do aquífero em termos de: (a) grau de consolidação e (b) litologia, assinalando um índice a este parâmetro em uma escala de 0,4 a 1,0, conforme ilustra figura 2 .

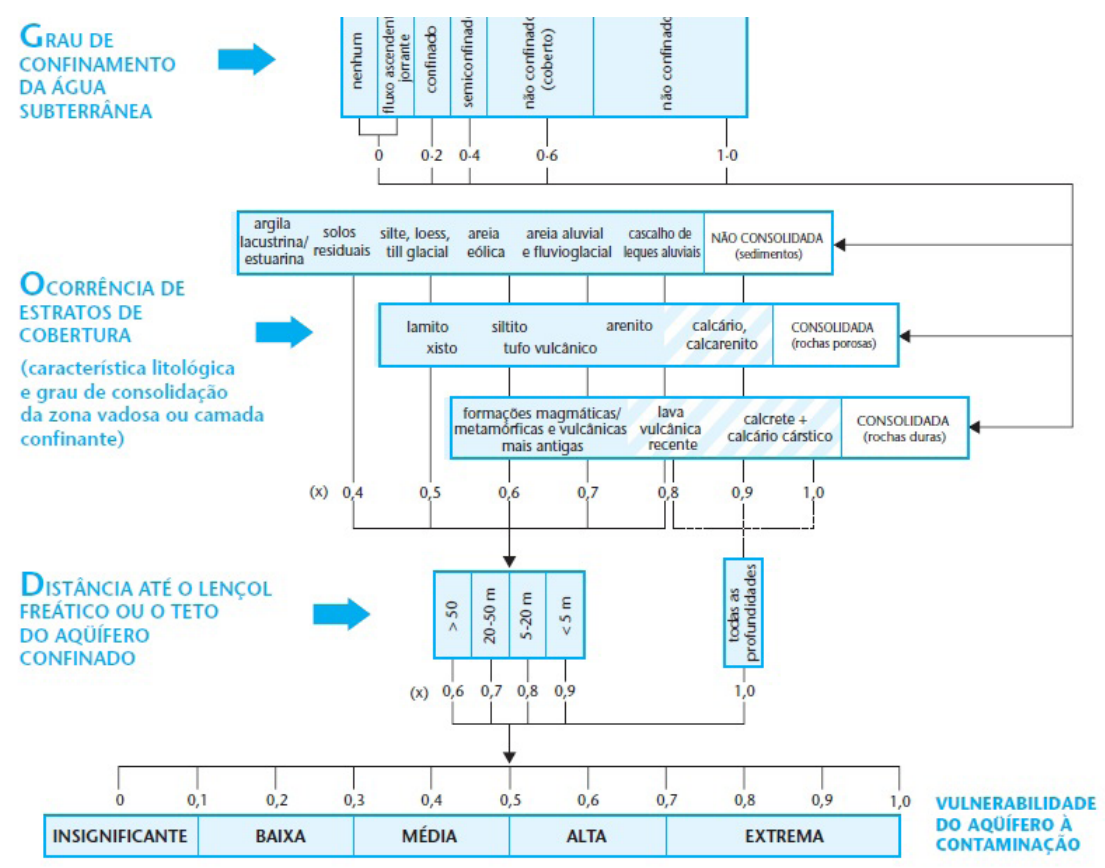

Figura 2. Sistema GOD para avaliação da vulnerabilidade do aquífero

Fonte: FOSTER et al. (2006). 
Considerou-se distância ou profundidade ao nível da água (em aquíferos não confinados) ou profundidade do teto da camada do primeiro aquífero confinado, assinalando um índice a este parâmetro em uma escala de 0,6 a 1,0.

O índice final integrado da avaliação de vulnerabilidade do aquífero à contaminação "GOD" é o produto dos valores obtidos para cada um dos parâmetros, variando de 0,0 (insignificante) até 1,0 (extrema) e pode ser observado no Quadro 1.

Para espacialização dos dados e construção dos mapas de vulnerabilidade em coordenadas Universal Transversa de Mercator (UTM) foi utilizado o programa Surfer 9. Utilizou-se o Datum Horizontal SAD-69 e Datum Vertical o Porto de Imbituba-SC, inseridos no fuso 22 que apresenta como meridiano central $51^{\circ}$ a oeste de Greenwich. Utilizou-se a krigagem como método de interpola- ção matemática, que melhor ajustou-se aos dados.

\section{RESULTADOS E DISCUSSÃO}

Este método avalia a vulnerabilidade do aquífero a partir dos dados obtidos no sítio do SIAGAS/CPRM, foi elaborado o quadro 1, que contem o banco de dados hidrogeológico com informações das captações de Seberi/RS: Coordenadas UTM; código SIAGAS; cota do terreno; $\mathrm{G}=$ Nota do Grau de confinamento do aquífero; Geologia/litologia; O=Nota da Ocorrência litológica; Nível Estático; $\mathrm{D}=$ Nota da profundidade do nível estático; IV=Índice Numérico de Vulnerabilidade do aquífero à contaminação GOD; Vulnerabilidade do aquífero à contaminação GOD e Cor de representação no mapa.

\begin{tabular}{|c|c|c|c|c|c|c|c|c|c|c|c|c|}
\hline UTM E & UTM N & $\begin{array}{c}\text { Código } \\
(43000+)\end{array}$ & \begin{tabular}{|c|} 
Cota do \\
terreno $(\mathrm{m})$
\end{tabular} & Município (RS) & Condição & G & Geologia & $\mathrm{O}$ & \begin{tabular}{|c|} 
Nível \\
Estático(m)
\end{tabular} & $\mathrm{D}$ & IV & $\begin{array}{l}\text { Vulnerabili- } \\
\text { dade }\end{array}$ \\
\hline 276786 & 6963077 & 17314 & 347 & Cristal do Sul & Livre & 1 & Fm. Serra Geral & 0.8 & 14.78 & 0.8 & 0.64 & Alta \\
\hline 279470 & 6966632 & 15405 & 267 & Cristal do Sul & Livre & 1 & Fm. Serra Geral & 0.8 & 12.00 & 0.8 & 0.64 & Alta \\
\hline 256071 & 6963937 & 17346 & 386 & $\begin{array}{l}\text { Taquaruçu do } \\
\text { Sul } \\
\end{array}$ & Livre & 1 & Fm. Serra Geral & 0.8 & 8 & 0.8 & 0.64 & Alta \\
\hline 267550 & 6924796 & 12334 & 624 & $\begin{array}{l}\text { Boa Vista das } \\
\text { Missões }\end{array}$ & Livre & 0.6 & Fm. Serra Geral & 0.8 & 50.66 & 0.6 & 0.28 & Baixa \\
\hline 271349 & 6926992 & 12332 & 603 & $\begin{array}{c}\text { Boa Vista das } \\
\text { Missões }\end{array}$ & Livre & 1 & Fm. Serra Geral & 0.8 & 14.00 & 0.8 & 0.64 & Alta \\
\hline 271580 & 6938449 & 12337 & 583 & $\begin{array}{l}\text { Boa Vista das } \\
\text { Missões }\end{array}$ & Livre & 1 & Fm. Serra Geral & 0.8 & 10.00 & 0.8 & 0.64 & Alta \\
\hline 272169 & 6942889 & 12340 & 542 & $\begin{array}{c}\text { Boa Vista das } \\
\text { Missões }\end{array}$ & Livre & 0.6 & Fm. Serra Geral & 0.8 & 47.00 & 0.7 & 0.33 & Média \\
\hline 275209 & 6931646 & 12331 & 537 & $\begin{array}{l}\text { Boa Vista das } \\
\text { Missões }\end{array}$ & Livre & 0.6 & Fm. Serra Geral & 0.8 & 99.85 & 0.6 & 0.28 & Baixa \\
\hline 262015 & 6972140 & 2379 & 520 & $\begin{array}{c}\text { Frederico } \\
\text { Westphalen }\end{array}$ & Livre & 1 & Fm. Serra Geral & 0.8 & 2.50 & 0.9 & 0.72 & Extrema \\
\hline 262155 & 6970380 & 2017 & 505 & $\begin{array}{c}\text { Frederico } \\
\text { Westphalen }\end{array}$ & Livre & 0.6 & Fm. Serra Geral & 0.8 & 114.50 & 0.6 & 0.28 & Baixa \\
\hline 262205 & 6972100 & 2378 & 520 & $\begin{array}{c}\text { Frederico } \\
\text { Westphalen }\end{array}$ & Livre & 1 & Fm. Serra Geral & 0.8 & 3.00 & 0.9 & 0.72 & Extrema \\
\hline 264140 & 6970300 & 2018 & 520 & $\begin{array}{c}\text { Frederico } \\
\text { Westphalen }\end{array}$ & Livre & 0.6 & Fm. Serra Geral & 0.8 & 114.40 & 0.6 & 0.28 & Baixa \\
\hline 262074 & 6957104 & 17122 & 474 & Seberi & Livre & 0.6 & Fm. Serra Geral & 0.8 & 64 & 0.6 & 0.28 & Baixa \\
\hline 262225 & 6957975 & 2445 & 510 & Seberi & Livre & 1 & Fm. Serra Geral & 0.8 & 20.76 & 0.7 & 0.56 & Alta \\
\hline 262600 & 6958040 & 2441 & 545 & Seberi & Livre & 1 & Fm. Serra Geral & 0.8 & 21.2 & 0.7 & 0.56 & Alta \\
\hline 262930 & 6957000 & 2443 & 500 & Seberi & Livre & 0.6 & Fm. Serra Geral & 0.8 & 93.7 & 0.6 & 0.28 & Baixa \\
\hline 263012 & 6957138 & 2449 & 515 & Seberi & Livre & 0.6 & Fm. Serra Geral & 0.8 & 94.34 & 0.6 & 0.28 & Baixa \\
\hline 263015 & 6957150 & 2442 & 515 & Seberi & Livre & 0.6 & Fm. Serra Geral & 0.8 & 113.2 & 0.6 & 0.28 & Baixa \\
\hline 263135 & 6957670 & 2444 & 540 & Seberi & Livre & 1 & Fm. Serra Geral & 0.8 & 19.04 & 0.8 & 0.64 & Alta \\
\hline
\end{tabular}

Quadro 1. Banco de dados Hidrogeológico com informações referentes às captações avaliadas no município de Seberi/RS. 
Como observado no quadro 1 e na Figura 2, a vulnerabilidade do aquífero à contaminação no município de Seberi/RS variou de Baixa até Alta. A área urbana do Município apresentou os índices baixo, médio e alto de vulnerabilidade, sendo que o índice mostrou-se crescente na direção sudoeste para nordeste do município de Seberi.

Já no trabalho desenvolvido por KEMERICH et al (2013) utilizando a mesma metodologia, porém em uma bacia hidrográfica com formação geológica diferente, a vulnerabilidade variou de insignificante a extrema. Nas águas subterrâneas da bacia hidrográfica do Rio Vacacaí-Mirim, foi possível observar que existem áreas com vulnerabilidade extrema, em função dos níveis estáticos próximos a superfície incluindo surgências em alguns casos, e das formações geológicas com alta permeabilidade (Formação Serra Geral, Aluvião e Terraços Fluviais).

Foi possível identificar que alguns municípios da região apresentam uma alta vulnerabilidade, sendo assim mais susceptível a contaminação dos recursos subterrâneos.

FERNANDES et al. (2011) na observação de 10 poços na cidade de Constântina-RS, cidade próxima a Seberi, relatam que a vulnerabilidade variou de insignificante a baixa, provavelmente devido a formação geológica do município.

No estudo realizado utilizando a mesma metodologia por ALBERTI \& SILVA (2005) em Tupanciretã-RS, foram encontradas duas classes, sendo 6 poços com vulnerabilidade alta e 8 poços com vulnerabilidade média de contaminação dos aquíferos.

\section{CONCLUSÃO}

A elaboração do mapa da vulnerabilidade do aquífero à contaminação através do método GOD contribuiu para a espacialização desta no município de Seberi/RS e por sua vez representa

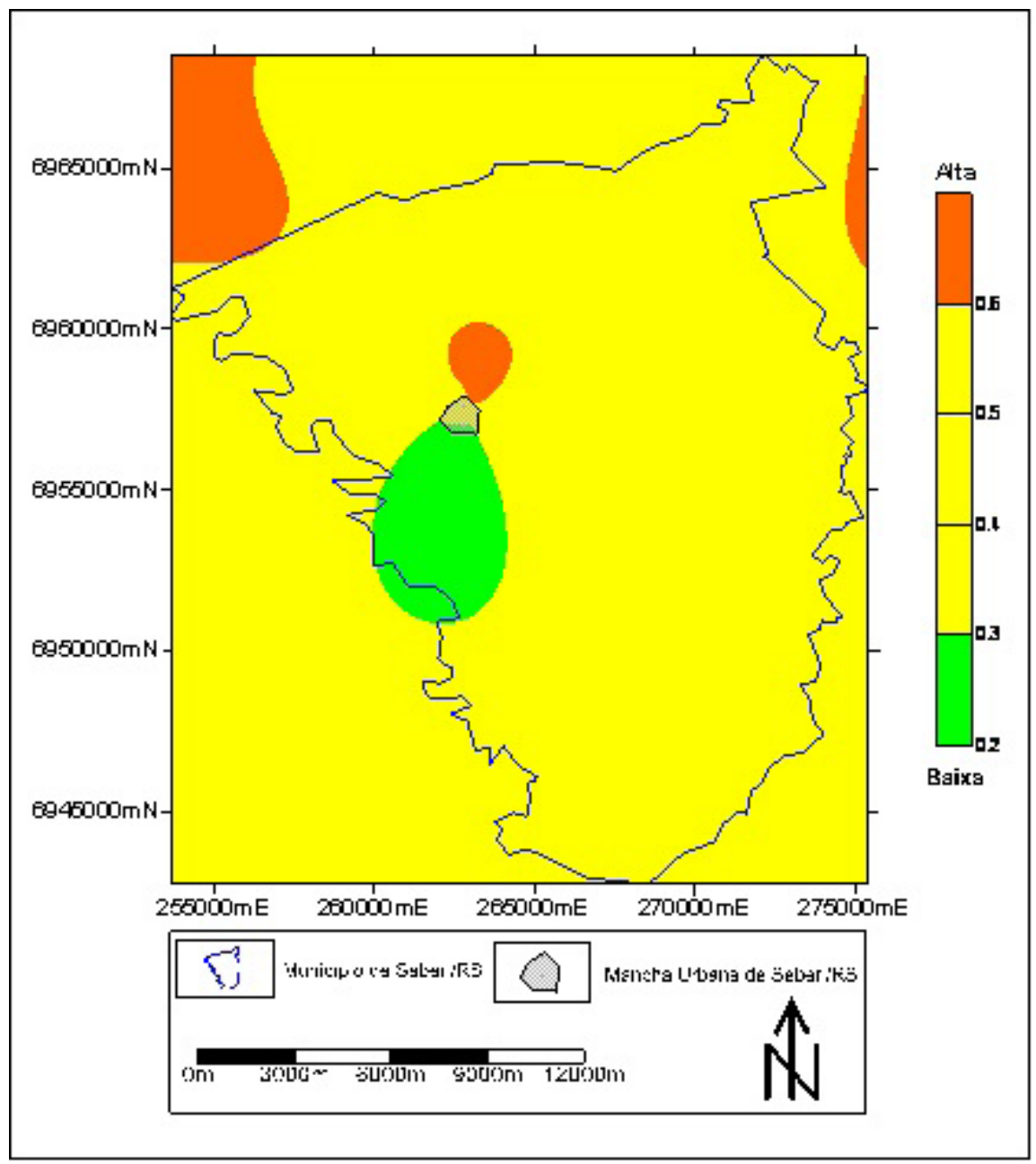

Figura 2. Cartograma da vulnerabilidade do aquífero à contaminação no Município de Seberi/RS através do método GOD de Foster et al. (2006). 
uma importante ferramenta para gestão das águas subterrâneas deste município colaborando para manutenção e reconhecimento da qualidade das águas subterrâneas e para o manejo e gestão ambiental, visando à manutenção dos recursos hídricos subterrâneos em excelente estado para atuais e futuras gerações.

Com esse trabalho foi possível apresentar quais as regiões são mais susceptíveis a contaminação dos recursos hídricos subterrâneos, tão utilizados atualmente pelas comunidades. Com esses dados pode-se estabelecer antes da construção de poços tubulares, a qualidade desta água através dos dados de vulnerabilidade á contaminação da região.

Após a conclusão de trabalhos como esse, vale ainda salientar a importância de se cadastrar os poços tubulares junto ao sistema SIAGAS, uma vez que a partir das informações prestadas nesse cadastramento, podem ser desenvolvidos estudos com a finalidade de melhor gerenciamento e conservação das águas subterrâneas.

\section{REFERÊNCIAS}

ALBERTI, E.A.; DA SILVA J.L.S. Estudo da vulnerabilidade natural dos aqǘferos no perímetro urbano de Tupanciretã/RS. I ${ }^{\circ}$ SIMPÓSIO DE RECURSOS HÍDRICOS DO SUL, I SIMPÓSIO DE ÁGUAS DA AUGM, 2005. Anais eletrônicos... Santa Maria: UFSM, 2005. Disponível em: http://jararaca. ufsm.br/websites/labhidro/download/105.pdf. Acessado em: 10 de Julho de 2013.

ALLER, L.; BENNET, T.; LEHR, J.H.; PETTY, R.J. DRASTIC: a standardized system for evaluating groundwater pollution potential using. Ohio: National Water Well Association, 1987.

BRASIL. Instituto Brasileiro de Geografia e Estatística - IBGE. Contagem da População. Rio de Janeiro: 2007.

\section{COMPANHIA DE PESQUISA E RECURSOS} MINERAIS, CPRM. Mapas Geológicos. Escala 1:100.000, Anexos 67, 68, 77, 78, 79, 80, 89, 90, 91 e 92. Projeto Borda Leste da Bacia do Paraná Integração Geológica e Avaliação Econômica. Brasília: CPRM, 1986.

CUTRIM, A. O.; CAMPOS, J. E. G. Avaliação da vulnerabilidade e perigo à contaminação do aquífero furnas na cidade de Rondonópolis (MT) com apli- cação dos métodos GOD e POSH. Revista Geociências, Vol.29, n.3, p. 401-411, 2010.

FERNANDES, G. D. A.; KEMERICH, P. D. C.; FLORES, B. A.; FRANCA, J. R.; BORBA, W. F. Caracterização das fontes alternativas de abastecimento de água em Constantina-RS. XXVI JORNADA ACADÊMICA INTEGRADA, 2011. Anais Eletrônicos... Santa Maria: UFSM, 2011. Disponível em: http://portal. ufsm.br/jai/anais/trabalhos/trabalho_1001221110. htm. Acessado em: 10 de Julho de 2013.

FOSTER, S. S. D.; HIRATA, R. GOMES, D.; D’ELIA, M.; PARIS, M. Proteção da Qualidade da Água Subterrânea: um guia para empresas de abastecimento de água, órgãos municipais e agencias ambientais. Wasshington: Groundwater Management Advisory GW, 2006.

FOSTER, S.; HIRATA, R. Determinação do risco de contaminação das águas subterrâneas: um método baseado em dados existentes. São Paulo: Instituto Geológico, 1993.

FOSTER, S. S. D.; HIRATA, R. C. A. Groundwater pollution risk evaluation: the methodology using available data. Lima: WHO/PAHO/HPE/CEPIS, 1987.

IG/CETESB/DAEE. Mapeamento da vulnerabilidade e risco de poluição das águas subterrâneas no Estado de São Paulo. São Paulo: IG/CETESB, 1997.

KEMERICH, P. D. da C.; MARTINS, S. R.; KOBIYAMA, M.; SILVEIRA, R. L.; DESCOVI FILHO, L.; RIZZARDI, A. S.; BORBA, W. F. Vulnerabilidade natural à contaminação da água subterrânea na bacia hidrográfica do Rio Vacacaí-Mirim: uso da metodologia GOD. Revista Engenharia Ambiental (Online), Vol. 10, p. 189-207, 2013.

MACHADO, J. L. F., Freitas, M. A. de. Projeto mapa hidrogeológico do Rio Grande do Sul: relatório final e mapa. Porto Alegre: CPRM, 2005. 65p.

MEDEIROS, C. M. Mapeamento da vulnerabilidade de parte da Bacia Sedimentar do Baixo Curso do rio Paraíba utilizando o método GOD. XV SIMPÓSIO BRASILEIRO DE SENSORIAMENTO REMOTO, 2011. Anais eletrônicos... Curitiba: INPE, 2011. Disponível em: http://www.dsr.inpe.br/sbsr2011/ files/p0296.pdf. Acessado em: 10 de Julho de 2013.

NANNI, A. S.; TEDESCO, M. A.; FREITAS, M. A.; BINOTTO, R. B. Vulnerabilidade natural e risco 
de contaminação do aquífero serra geral pela suinocultura na região das missões - RS. XVI SIMPÓSIO BRASILEIRO DE RECURSOS HÍDRICOS, 2005. Anais eletrônicos... João Pessoa: ABAS, 2005. Disponível em: http://www.dpi.inpe.br/spring/portugues/arquivos publicacoes/xvi sbrh.pdf. Acessado em: 10 de Julho de 2013.

NANNI, A. S. O Flúor em águas do Sistema Aquífero Serra Geral no Rio Grande do Sul: origem e condicionamento geológico. 120f. 2008. Tese (Doutorado em Geociências) - Programa de Pós-Graduação em Geociências, Universidade Federal do Rio Grande do Sul, Porto Alegre, 2008.

PRESOTTO, C. A.; DIAS, A.; KIRCHNER, A.; GARCIA, P. F. Projeto hidrogeologia da fronteira sudoeste do Rio Grande do Sul. Relatório Final.. Porto Alegre: CPRM, 1973.

RIBEIRO, L. IS: um novo índice de vulnerabilidade específico de aquíferos: formulação e aplicações. Rio de Janeiro: ERSHA-CVRM, 2000.

RIBEIRO, L. Vulnerabilidade de aquíferos: conceitos, métodos e práticas. Lisboa: FTD, 2004. 